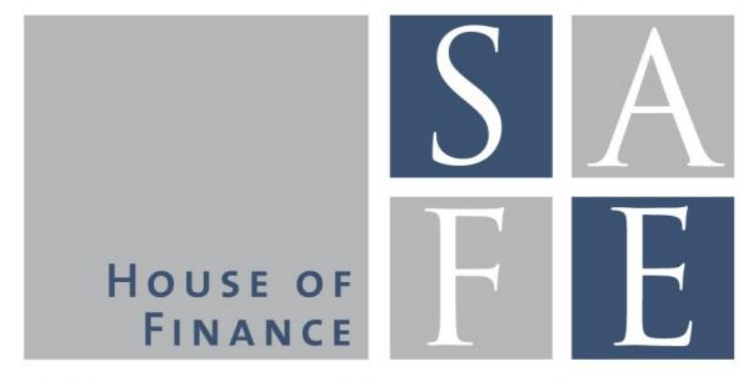

WORKING PAPER SERIES

Guido Friebel - Marie Lalanne - Bernard Richter - Peter Schwardmann Paul Seabright

\title{
Women form social networks more selectively and less opportunistically than men
}

SAFE Working Paper No. 168

SAFE I Sustainable Architecture for Finance in Europe A cooperation of the Center for Financial Studies and Goethe University Frankfurt 


\section{Non-Technical Summary}

Social networks are important for many economic outcomes. They influence how people get a job, with whom they collaborate, and how their careers evolve. Previous case studies have uncovered that the social networks of men and women differ, but little is known about what causes these differences. Importantly, differences in men's and women's social networks may be key in understanding persistent gender differences in career outcomes and may complement existing explanations of the observed gender gaps in labor market outcomes.

This paper investigates whether gender differences in the shape and size of social networks are the result of gender differences in preferences, rather than merely the result of the constraints society imposes on women.

In laboratory experiments with cohorts of new students at Goethe University Frankfurt, we show that women are more selective in forming networks and only half as reactive as men to information about the economic benefits of interacting with different individuals. Women's social networks outside the lab are also more dominated by contacts they make early on at university. This evidence is in line with previous studies showing that women's social networks are more stable, path-dependent and composed of a greater proportion of strong relative to weak links.

If men are more opportunistic about the formation of networks, as our results suggest, they may benefit in two distinct ways: They may invest more in sustaining weak links in their social networks, and they may be more likely than women to call in favors from their casual acquaintances when looking for new employment. These behaviors are likely to make them more visible in their professional network - and in particular in high-skill professional networks - which might in turn generate career benefits. 


\title{
Women form social networks more selectively and less opportunistically than men
}

\author{
Guido Friebel*, Marie Lalanne ${ }^{\dagger}$, Bernard Richter ${ }^{\ddagger}$, \\ Peter Schwardmann ${ }^{\S}$ and Paul Seabright ${ }^{\Uparrow}$
}

March 2017

\begin{abstract}
We test two hypotheses, based on sexual selection theory, about gender differences in costly social interactions. Differential selectivity states that women invest less than men in interactions with new individuals. Differential opportunism states that women's investment in social interactions is less responsive to information about the interaction's payoffs. The hypotheses imply that women's social networks are more stable and path dependent and composed of a greater proportion of strong relative to weak links. During their introductory week, we let new university students play an experimental trust game, first with one anonymous partner, then with the same and a new partner. Consistent with our hypotheses, we find that women invest less than men in new partners and that their investments are only half as responsive to information about the likely returns to the investment. Moreover, subsequent formation of students' real social networks is consistent with the experimental results: being randomly assigned to the same introductory group has a much larger positive effect on women's likelihood of reporting a subsequent friendship.
\end{abstract}

JEL codes: C91, D81, J16

Keywords: Social Networks, Gender Differences, Trust Game

*Goethe University Frankfurt; gfriebel@ wiwi.uni-frankfurt.de

${ }^{\dagger}$ Goethe University Frankfurt and SAFE Research Center; lalanne@safe.uni-frankfurt.de

${ }^{\ddagger}$ RCON Consulting UG; bernardr@gmx.de

${ }^{\S}$ University of Munich (LMU); peter.schwardmann@econ.lmu.de

`Toulouse School of Economics and University of Toulouse Capitole (IAST); Paul.Seabright@ tse-fr.eu

We gratefully acknowledge funding from ANR Labex-IAST and from the Research Center SAFE, funded by the State of Hessen initiative for research LOEWE. 


\section{Introduction}

Social networks affect many important economic outcomes. They influence who gets hired, with whom people collaborate, and how careers evolve (Brown et al. 2016; Burks et al. 2015; Cingano and Rosolia 2012; Dustmann et al. 2016). However, much remains to be understood about why individuals' networks differ. Our paper investigates the underlying reasons for important differences between the shape of men's and women's social networks.

Early work by Granovetter $(1973,1995)$ distinguishes between strong links, i.e. close relationships, and weak links, i.e. more casual and opportunistic acquaintanceships. He hypothesizes that, paradoxically, weak links are often more useful in contexts like job search where acquaintances' greater ability to provide novel information outweighs their lesser motivation to provide support and help. By facilitating information acquisition, weak links are also more likely to be useful in situations of high uncertainty such as high-level and highly-rewarding positions.

A rich case study literature suggests that women tend to have smaller social networks than men and that women's networks feature more strong links and fewer weak links (Booth 1972; Moore 1990; Benenson 1993; Baumeister and Sommer 1997). Moreover, recent evidence supports the view that women and men leverage their networks differently (Mengel 2016; Beaman et al. 2015) and obtain different work-related benefits because of different network structures (Lindenlaub and Prummer 2015; Lalanne and Seabright 2016). Differences in men's and women's social networks may therefore be key in understanding gender differences in career outcomes and may complement existing explanations of the persistent gender gap in labor market outcomes (see Bertrand (2011) for a recent survey).

This paper investigates whether gender differences in the shape and size of social networks are the result of gender differences in preferences, rather than merely the result of the constraints society imposes on women. The distinction between preferences and constraints is of first order importance, because they require different policy responses. If differences in social networks are mainly the result of constraints, it may be possible to legislate these constraints away. If preferences also matter, social science should seek to document the economic costs of these preferences and where the costs are underappreciated, policy can play a useful role in communicating them.

Using data from a laboratory and a natural experiment, we test two hypotheses, derived from sexual selection theory, about how men and women build their social networks. The hypothesis of differential selectivity states that women are more selective than men when assessing a novel part- 
nership - they invest less in a new interaction. The differential opportunism hypothesis states that women's investment is less responsive than men's to information about the likely economic payoff to investing in a given partner.

Even small differences in the way men and women approach new and respond to past social interactions may result in large differences in the network structures that evolve over time. Taken together our hypotheses imply that women's networks will tend to differ on average from those of men, in being more stable, path dependent and composed to a greater degree of strong rather than weak links. Selectivity causes fewer new links to be formed. Since the time, energy and other resources a person can commit to social interactions are limited, fewer new links imply that more resources can be allocated to existing links and their maintenance. This would cause women's networks to be more stable and consist of stronger ties. Lower opportunism further contributes to network stability and path-dependence, since new opportunities are less likely to divert investments from existing links.

Notice that our hypotheses do not imply that women are less economically rational than men. First, economic rationality is compatible with widely different degrees of selectivity about entering into relationships. Second, economic rationality is not the same as opportunism; indeed it is well known that too much opportunism may be damaging to economic payoffs in the long run. However, in the context of modern labor markets, especially for senior appointments, the lesser opportunism of women's networks may constitute an economic disadvantage.

Human relationships involve an inescapable element of trust, which is why our laboratory experiment uses a trust game to understand the structure and formation of reciprocal networks. This contrasts with most existing models and experiments of network formation, which make the simplifying assumption that individuals can build deterministic links at a cost (e.g. see Kosfeld 2004; Jackson 2008). While useful for many purposes, such an approach does not take into account the fact that many network connections have to be reciprocal if they are to be of any value. Individuals may have to make investments of time, emotional energy, economic resources or even exposure to significant personal risk in order to establish connections. Yet they cannot find out whether their investments will be reciprocated until they are sunk, so that reliance on the trustworthiness of others is unavoidable.

Student newcomers to Frankfurt University were randomly allocated to gender-balanced introductory week groups in which they interacted for their first week on campus. As part of this process, we recruited for our experiment 341 of these students (196 men and 145 women) for our laboratory experiment, in which they played two rounds of trust games with anonymous partners. 
In our experimental design, subjects play a classic trust game in the first round. The sender sends any amount of tokens from his endowment to the receiver. The amount sent is tripled by the experimenters. The receiver can then return any sum from the tripled amount he received. After observing the results of playing with the partner from the first round, subjects play a second round, which, in order to eliminate dynamic strategic considerations, comes as a surprise to subjects. In this round, subjects have the option of continuing to play with their old partner as well as the option of playing with a new anonymous partner. Each subject plays the role of both sender and receiver simultaneously with each partner in each round.

The results support both our hypotheses: women send less on average to new partners than men, and they respond less to the information revealed in the first round when deciding how much to send in the second round.

Some months after the experiment, we elicited evidence from questionnaires about subjects' networks of friendships and acquaintanceships with other students in their cohort, to test whether their real networks had developed along the lines suggested by their behavior in the lab. In particular, we expected women's networks to be more stable and path-dependent than men's. Here, we were able to exploit a natural experiment. Because students were randomly assigned to gender balanced introductory groups, there was exogenous variation in the set of potential acquaintances to which each student was initially exposed, but not substantially in the overall proportion of men and women in these groups. The balanced gender ratio of introductory groups thus assured that homophily - preference for same gender in our setting - was not a confound of preferences for network formation. For example, in a group with more men than women, homophily would imply that men will have more links and that, because social resources are finite, these links are weaker; our experimental design was able to avoid this problem.

We find a striking gender difference in the impact of initial assignments of students to introductory groups. While two men who had been randomly assigned to the same introductory group are two-and-a-half times more likely to both report a subsequent friendship than two men who were in different groups, two women from the same group are five times more likely to report a subsequent friendship than two women who were in different groups. 


\subsection{Evolutionary foundation}

A number of sources provide the basis for our hypotheses. Darwin (1871) hypothesizes that females of all species are more selective than males about undertaking sexual partnerships. Trivers (1972) locates the foundations of this preference in the asymmetry of parental investment made by males and females. Owing to the difference in gamete size and compounded in many animals by the asymmetric costs of gestation, sexual encounters have higher opportunity costs for females, and natural selection might therefore have led females to be more selective about such encounters.

Crucially, the logic of sexual selection also extends to other social interactions: Low (2001) investigates coalition formation in general, especially in group-living primates. Social coalitions have fitness consequences for both sexes, and the consequences of individual interactions tend to be higher for females than for males because of the impact on their dependent offspring. Hrdy (2009) emphasizes the centrality of cooperative parenting in human societies, stressing that infant survival depends critically on mothers' ability to engage in sustainable partnerships with group members other than the biological father. So the greater selectivity of females is likely to extend more generally to social interactions that are unrelated to producing or taking care of offspring directly, and so is the lower responsiveness of females to opportunities for interacting outside current partnerships. Empirical confirmation of these sex differences for primate behavior are reported in De Waal (1990, especially p.51). Seabright (2012) summarizes the implications of this literature for human beings, and in particular for the way in which men and women form coalitions and networks.

\subsection{Related experimental evidence}

Croson and Gneezy (2009) review twenty trust game experiments that analyze gender differences in subjects' behavior. Similarly to our work, the majority of papers find that men are more trusting than women. However, most of these experiments focus on trusting and reciprocal behavior towards a randomly assigned partner. On the contrary, we are interested in how men and women choose their partners when they have the possibility to do so.

To our knowledge, only a few experiments involving trust games allow for the active selection of interaction partners. Eckel and Wilson (2000) allow subjects to choose between two partners labeled with facial icons. Slonim and Garbarino (2008) and Slonim and Guillen (2010) allow subjects to choose between partners that are identified by their gender and age, and by their gender and a score in an addition task. Fiedler et al. (2011)'s experimental design is the most closely related to ours: subjects have the possibility to engage in 10 minutes of virtual communication before playing a trust 
game together or with an unknown partner. The four experiments find that selection significantly increases trust. Contrary to our work, they provide information on potential partners that is not directly related to the trusting decision (e.g. facial icons chosen by potential partners, demographic characteristics such as age and gender, ability in a task unrelated to the trust game, and information from virtual communication). We are interested in how previous interactions affect future interactions between two individuals and focus on how this differs between men and women. This question is of interest for understanding how men and women interact socially, and specifically for casting light on differences in the size and composition of the resulting networks.

\section{Design}

Our experimental design combines traditional questionnaires, laboratory experiments and online questionnaires. Student subjects were recruited from amongst all incoming business and economics students at the Goethe University Frankfurt. A detailed description of each stage is provided in the following subsections.

\subsection{Recruitment and initial questionnaire}

During their introductory week, every student received a unique id and cover letter. Every student was asked to respond to a questionnaire and to participate in a Holt and Laury (2002) risk elicitation task. The participant pool consisted of two cohorts of students. The first cohort with 328 registered students was questioned in the summer term 2012, the second with 467 registered students in the winter term 2012/13. We got 267 (436) questionnaires resulting in a participation rate of 81.4 (93.4) percent for the first (second) cohort ${ }^{1}$.

\subsection{Laboratory experiment}

Two weeks after the introductory week, students were invited to our experiment at the Frankfurt Laboratory for Experimental Economics (FLEX). In total, 128 (213) students of the first (second) cohort participated in the experiment ${ }^{2}$. We obtained matching questionnaire and experimental data

\footnotetext{
${ }^{1}$ In the first wave we chose 24 subjects to receive their actual payoff of the Holt and Laury (2002) lottery. On average, students that were paid earned 25.1 EUR. For the second wave we provided 5 EUR for every questionnaire participation and chose in total eight students to receive their actual lottery payoff. Subjects who were paid earned on average 25.6 EUR.

${ }^{2}$ Due to a programming error which incorrectly matched all participants with the same partner, we had to drop the data from one session, which corresponds to 22 subjects.
} 
of 102 (171) students, that is 38.2 (39.2) percent of the students who participated in the questionnaire. Subjects in the first (second) wave of the experiment earned on average 11.2 EUR (11.5 EUR) for an experiment that lasted for around an hour. 43 percent of all participants were women and the average age was 20.5 years. 55 percent originated from the Rhein-Main area.

Stage one - Trust game with one partner: Each subject is endowed with 10 tokens, where 1 token corresponds to 0.1 EUR. Subjects then make a decision in the role of a sender $\mathrm{S}$ of how much of the endowment she wants to allocate to her partner, the receiver R. Each token sent is tripled by the experimenter. Subjects are then also put in the role of the receiver and decide what to return to her partner for each possible amount her partner could have sent, i.e. we make use of the strategy method to elicit the back transfer of receivers (Brandts and Charness (2000)). Subjects in our experiment thus play two trust games simultaneously with the same partner: one as sender and one as receiver. Payoffs $\left(\pi_{i}\right)$ for stage 1 are:

$$
\begin{aligned}
\text { for the sender: } & \pi_{S}=E_{S}-x_{S}+x_{R} \\
\text { for the receiver: } & \pi_{R}=3 x_{S}-x_{R}
\end{aligned}
$$

where $E_{S}$ denotes the endowment of the sender and $x_{i}$ the transfers of the players in their respective roles $i \in\{S, R\}$.

Afterwards, we ask subjects to state their beliefs about the back transfer of their partner in the role of the receiver. We incentivize this step in the following way. If the guess of the back transfer is precisely the amount back transferred, subjects earn 8 additional points. If the guess is inaccurate by two (four) points, subjects receive 4 (2) additional points. Finally all guesses that vary by more than 4 points gain no additional points for the subject. In other words, the closer a subject's guess of the back transfer is to what was actually returned, the greater the additional payoff she earns.

Stage two - Trust game with an old and a new partner: The second stage comes as a surprise to subjects. Subjects can play again with the previous partner and/or a new partner, i.e., they are matched in (overlapping) groups of three. Each subject first decides in the role of the sender whether she wants to keep her single stage 2 endowment of 10 tokens or whether she wants to allocate tokens to the old and/or the new partner. Both transfers are tripled by the experimenter. In the role of receiver, subjects choose how much they want to return to the old partner as sender, or the new partner 
as sender for each possible amount her partners could have sent. Payoffs $\pi_{i}$ in stage 2 are:

$$
\begin{aligned}
& \text { for the sender: } \pi_{S}=E_{S}-x_{S_{\text {Old }}}-x_{S_{\text {New }}}+x_{R_{\text {Old }}}+x_{R_{\text {New }}} \\
& \text { for the old receiver: } \pi_{R_{\text {Old }}}=3 x_{\text {Sold }}-x_{R_{\text {Old }}} \\
& \text { for the new receiver: } \quad \pi_{R_{\text {New }}}=3 x_{S_{\text {New }}}-x_{R_{\text {New }}}
\end{aligned}
$$

where $E_{S}$ denotes the endowment of the sender and $x_{i}$ the transfers of the players, with $i \in\left\{S_{\text {Old }}, S_{\text {New }}, R_{\text {Old }}, R_{\text {New }}\right\}$. We again ask subjects about their beliefs regarding the back transfers of their old partner as receiver and their new partner as receiver. The incentives used for the belief elicitation are the same as in stage 1 .

Treatments: In addition to the baseline we describe above, we consider two treatments and their interaction. The purpose of these treatments is to explore important questions about gender differences in network formation for which sexual selection theory does not provide clear predictions: namely whether subjects respond differently to partners of different gender, and whether men and women respond differently to the framing of the choice in a way that emphasizes it as a commitment.

Each subject played stages one and two in only one of the treatments i.e., we follow a betweensubject design.

1. NoVar - This is our baseline treatment. In stage 1 of the experiment subjects simultaneously play two trust games, first in the role of a sender and thereafter as a receiver. In stage 2, this trust game is extended by a randomly assigned anonymous new partner. No additional information about the partners was given to the subjects.

2. T1 - In the threshold 1 treatment subjects are asked to state whether they want to send any tokens to the old and/or the new partner before being asked how many tokens they wish to transfer to each. If they answer "yes", the amount they send has to lie above a threshold of 1 . Since subjects are allowed to send zero token in the baseline treatment and can only send integer values of tokens, this choice in no way impacts on their action sets. All it does is to increase the salience of the distinction between sending something and sending nothing, and is therefore a pure framing treatment. The game played in the NoVar treatment and in the T1 treatment have identical payoffs. 
3. RG - In the revealed gender treatment subjects receive information about their two stage 2 partners' gender and age as well as the year their partners started their studies. This information is provided before stage 2 . Information other than gender was provided to limit experimenter demand effects that could arise from making it too obvious that we are interested in the gender dimension.

4. T1RG - This treatment combines the features of the RG and of the T1 treatment.

\subsection{Online questionnaire}

The last step of our study explores how subjects behave outside the laboratory. We exploited the particularity of the Goethe University introductory week, during which students are randomly allocated to gender-balanced groups to undertake socializing activities. Students usually start the first university year with almost non-existent social networks, and the introductory week provides them opportunities to meet other students thereby forming a social network.

Some months after the experiments we invited all subjects who participated in the questionnaire study to take a short online questionnaire using the survey system of the FLEX. We invited the first run after a period of two semesters (roughly six months) and the second run after a period of one semester (roughly three months). Unique access codes were sent by e-mail and we incentivized participation by announcing that 10 people would be remunerated for their responses. We elicited their risk aversion using the Eckel and Grossman (2008) lotteries and paid the 10 randomly drawn subjects according to their answer in that test.

The online questionnaire asked about the extent of students' continuing connections to other students. Subjects were asked to write down a list of (maximum) 15 other subjects' names and note whether these were friends or acquaintances. 208 out of the 341 experimental subjects agreed to complete the questionnaire.

\section{Results}

\subsection{Women are more selective than men}

Our differential selectivity hypothesis states that women will send less money than men to their partners when they play as senders in trust games. This applies both to the amount sent to the partner in the first stage and to the "new" partner in the second stage. Figure 1 provides these comparisons. 
Figure 1: Women send less to new partners

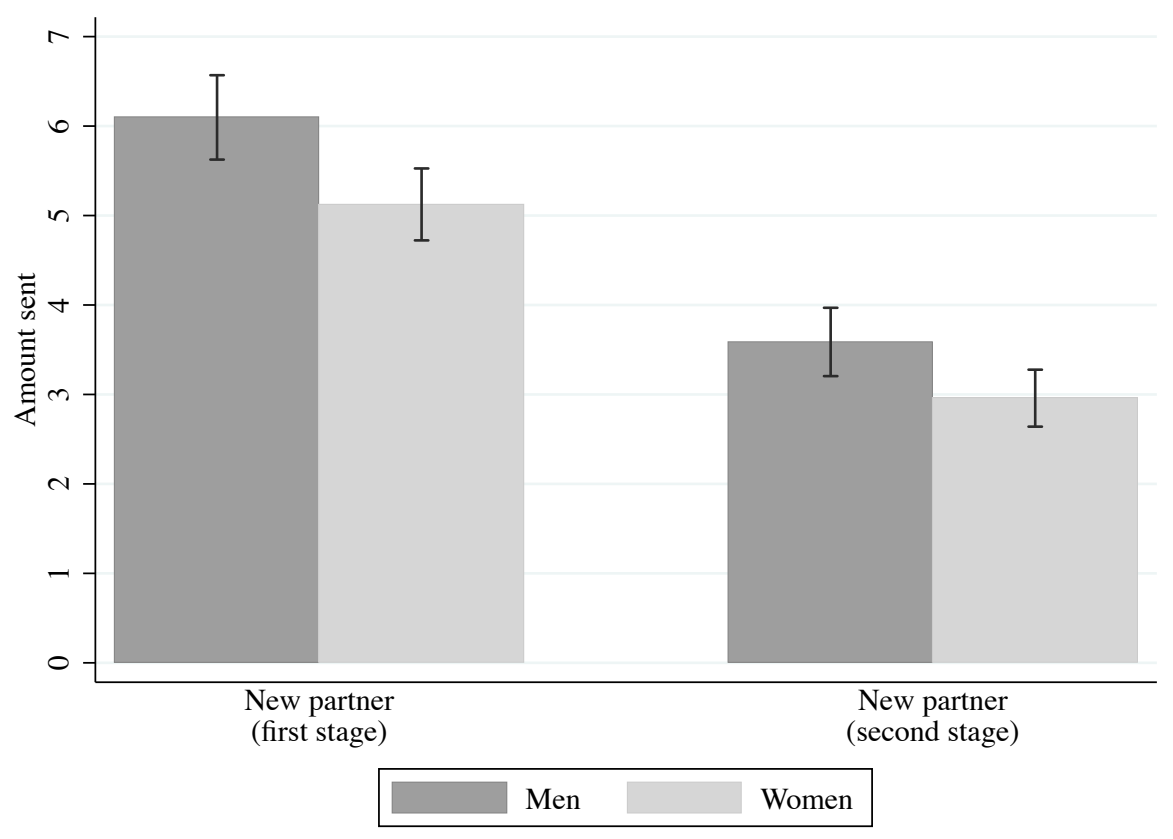

Women indeed send less money than men, a difference that is significant at the 1-percent level $(t=2.960$ and $p=0.003$ for the t-test on amounts sent in the first stage and $t=2.376$ and $p=0.018$ for the t-test on amounts sent to the new partner in the second stage).

As averages might hide important gender differences in the distribution, we plot the entire distribution in Figures A1 and A2 in the Appendix. The variance in amounts sent by men is higher in both cases, with standard deviations of 3.35 and 2.71 in the first and second stages, compared to 2.45 and 1.94 for women. Particularly strong evidence for differential selectivity is the fact that men are much more likely to send the whole endowment to their partner. A possible explanation for the observed difference might be gender specific differences in risk aversion. However, in an econometric analysis also presented in Table A1 in the Appendix, risk aversion fails to be significant in explaining the amounts sent by subjects.

We employ an additional test of selectivity that makes use of framing in order to make more salient the decision whether or not to continue the interactions with the old partner. In the treatment subjects were asked whether they wished to send anything at all to the old partner before entering the 
Figure 2: Women send less to old partners in framing treatment

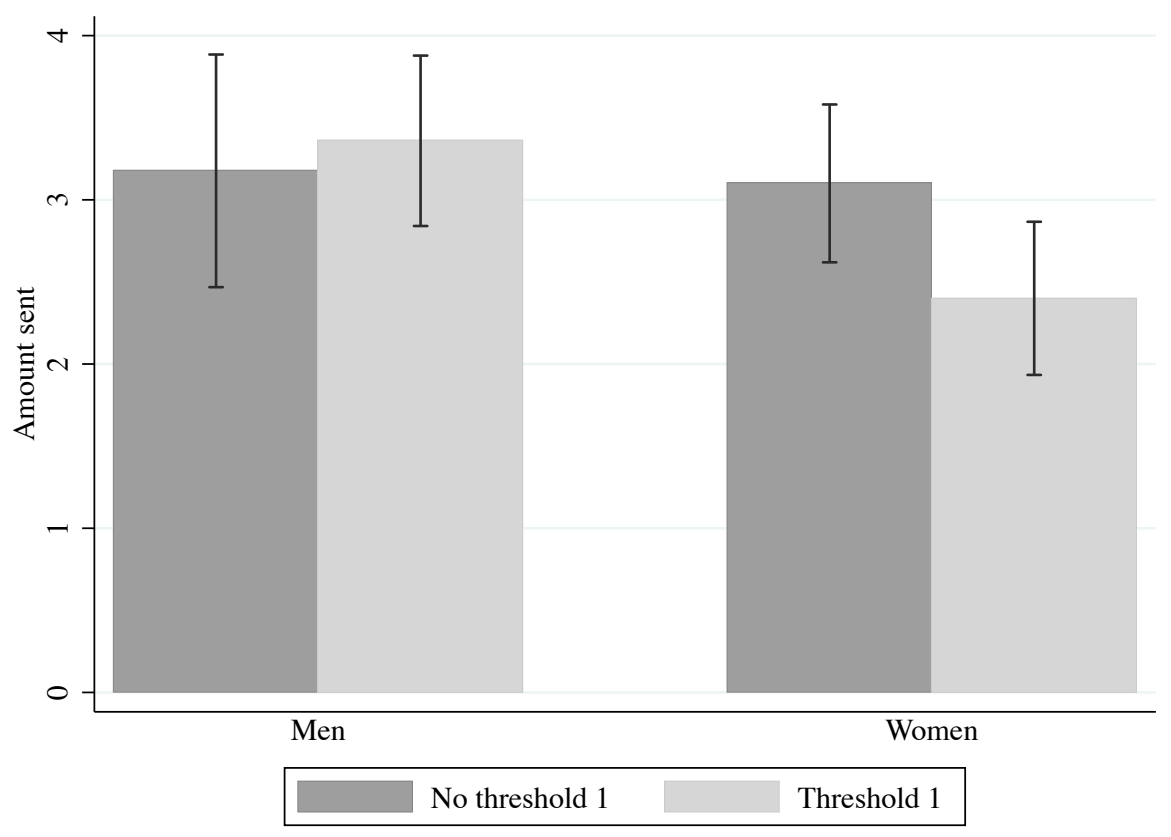

exact amount to be sent (which was not constrained from being zero in any of the treatments). This treatment did not affect the actions a subject could choose nor her possible payoffs, it merely made the option of not interacting, i.e. of being more selective, more salient. Our hypothesis was that women, but not men, send less to the old partner when primed with this reminder. Figure 2 shows that it is confirmed: women send 0.7 tokens less on average, a difference that is significant at 3.9 per cent.

The evidence presented here corroborates Hypothesis 1: women are more selective than men when entering a new partnership. They are more cautious and send lower amounts to their partners.

\subsection{Women are less opportunistic than men}

According to the differential opportunism hypothesis, women's investment is less responsive than men's to information about the likely economic payoff to sending money to a given partner. In the first stage, subjects have no information about their partner. In the second stage, subjects know both their old partner's behavior as a trustor and as a trustee (recall that every subject plays both roles). In principle, the partner's trustworthiness is the information most relevant to judging the likely returns 
Figure 3: Women are less responsive to old partners' rate of return

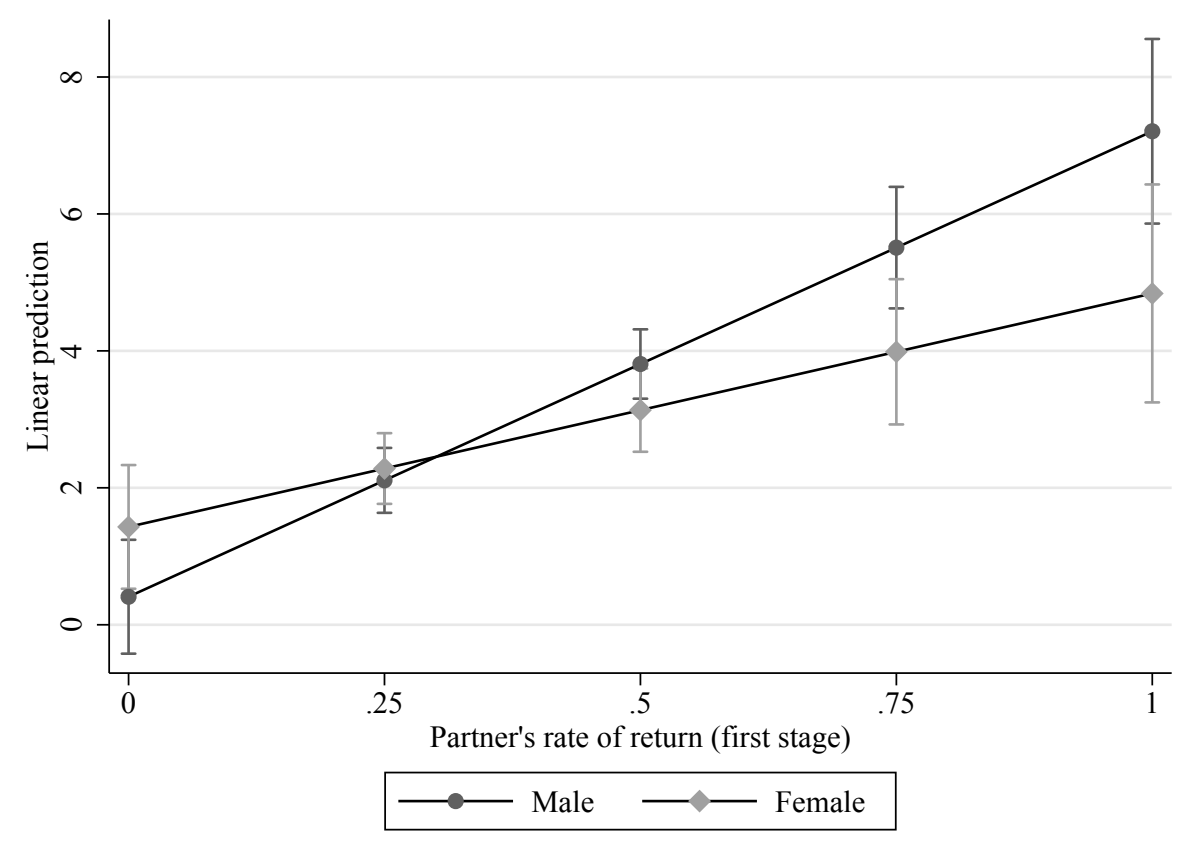

from sending money to the partner a second time. We expect that women will react less strongly than men to this information in their decision to play again with the old partner in the second stage. We nonetheless also control for information about the old partner's trustingness, which may induce a reciprocating response (though Hypothesis 2 does not predict any gender differences in this response).

Figure 3 shows the linear prediction of the amount sent to old partners in the second stage as a function of the return rate of the old partner in the first stage. Because net amounts returned depend on amounts sent in the first place, we computed the variable "return rate", which is defined as the amount the partner returned divided by the amount he received. We plot the marginal effects of old partner return rate on trust decisions in the second stage by gender, from a regression analysis presented below. As one would expect, the slope is positive for both men and women, but lower for women than for men.

We present here the corresponding econometric analysis. We focus on amounts sent by subjects in the second stage, as we are interested in the potentially different ways males and females invest in social interactions with known and unknown partners. We use Tobit analyses as our dependent variables will be censored (the amounts sent by subjects are necessarily in the interval between 0 and 
10). We estimate the following general model:

$$
\begin{aligned}
\text { Amount_Sent } & =\alpha_{0}+\alpha_{1} * \text { Female }+\alpha_{2} * \text { Beliefs }+\alpha_{3} * \text { Beliefs } * \text { Female } \\
& +\alpha_{6} * \text { Own_Amount_Sent }+\alpha_{7} * \text { Partner_Return_Rate } \\
& +\alpha_{8} * \text { Partner_Amount_Sent }+\alpha_{9} * \text { Partner_Return_Rate } * \text { Female } \\
& +\alpha_{10} * \text { Partner_Amount_Sent } * \text { Female }+\alpha_{101} * \text { RG_Treatment } \\
& +\alpha_{12} * \text { RG_Treatment } * \text { Female }+\alpha_{13} * T 1 \_T r e a t m e n t \\
& +\alpha_{14} * \text { T1_Treatment } * \text { Female }+\epsilon
\end{aligned}
$$

Here the variable Beliefs measures the senders' beliefs about the amounts that their partner will send back for any possible amount the partner may have received (more precisely, it represents the slope of the linear fit of expected amounts returned on possible amounts sent). We included the variable Own_Amount_Sent to capture the heterogeneity in amounts sent by subjects in stage 1, as this may represent otherwise unobserved heterogeneity in generosity or altruism. In order to investigate the effect of the partner's behavior in the first stage on subjects' behavior in the second stage, we include the variables Partner_Return_Rate and Partner_Amount_Sent and their interacted terms with the Female variable. We also control for treatments to which subjects where assigned. Table 1 presents the corresponding regression results.

There is a large and clearly significant difference (at 2.6 per cent) in the responsiveness of male and female subjects to the return rate of the old partner. Could other gender differences (analogous to differences in risk aversion) be at the root of these findings? Two alternative explanations suggest themselves: 1) females might be less able to predict the amount that will be returned by the partner and 2) females might be less confident in their evaluation of this amount. Statistics on beliefs and actual amounts returned show that the first of these alternatives is incorrect. The average difference between subjects beliefs and actual partners amounts returned is 0.732 for males and 1.201 for females, and this difference is not statistically significant. Males and females are equally able to predict what the partner will return to them. We can also reject the suggestion that the differences are due to differential confidence in the predictions of men and women: if this were so, there should be much less difference in men's and women's responsiveness to actual returns in the first stage than to beliefs in that stage, since the former are based on hard evidence while the latter are purely conjecture. In fact, as we can see, the gender differences are more pronounced for actual returns than for beliefs.

Overall, this evidence corroborates Hypothesis 2: women are less responsive than men to information about the likely economic payoff to an investment in network-building. 


\section{Homophily}

Although the revealed gender treatment is not significant in Table 1, there are more effects of revealing gender than are visible here. Since men and women send different amounts in total in the second stage, the effect of revealed gender is likely to be complicated by other influences on the total amount sent which the regression may not easily be able to control. Moreover, Table 1 only allows us to draw conclusions on how much subjects send to either a male or female partner as compared to an anonymous partner. How much subjects send to men rather than women is our question of interest. Table 2 therefore shows the determinants of the proportion of the total amount sent that is sent to the old partner, for the subset of subjects who face one male and one female partner in stage two, and know the gender of their partners (i.e. subjects that were assigned to the revealed gender treatment).

In specification I, we find that, other things equal, women appear to send a significantly larger proportion to their old partner. When we control also for whether the old partner is of the same gender as the subject, we can see in specification II that the effect in specification I is driven by the fact that females send much more to their old partner if the old partner is also female. Finally, in specification III, we slightly lose significance of results by adding the full set of controls (i.e. amounts sent and returned by the old partner interacted with the partner's gender). We interpret this finding as the partner's gender being less informative to subjects with respect to trust than the actual amounts sent and returned by the partner in the first stage. We also run equivalent regressions with the proportion sent to the new partner as the dependent variable and find that women sent much less to the new partner, especially if he is male. On the contrary, men sent much more to their new partner, especially if she is female.

These last results seem in line with our conjectures that women will prefer to invest in strong links (by sending more to their old partners), creating more stable and path dependent networks, while men will have a preference for weak links (by sending more to their new partners), creating more disperse and extended networks. The extra result that females prefer to interact with other females (homophily), while there is no evidence of homophily for males, implies that in populations that have less than 50\% women, such as for example the populations of top corporate executives or top political elites, women's networks are likely to be smaller. Moreover, if men have a greater tendency to reward their social contacts - as Mengel (2015) observes - women are likely to gain less network benefits compared to men. 
Table 1: Effect of partner's return rate on trust decisions

\begin{tabular}{lcc}
\hline Dependent Variable: & $\begin{array}{c}\text { Amount Sent to } \\
\text { OLD Partner }\end{array}$ & $\begin{array}{c}\text { Amount Sent to } \\
\text { NEW Partner }\end{array}$ \\
\hline Independent Variables & & \\
\hline Female & $3.091^{* *}$ & -1.899 \\
& $(1.313)$ & $(1.155)$ \\
Beliefs & $1.121^{* * *}$ & $0.812^{* * *}$ \\
Beliefs*Female & $(0.398)$ & $(0.342)$ \\
& -0.940 & -0.208 \\
Partner's Return Rate & $(0.585)$ & $(0.520)$ \\
Partner's Return Rate*Female & $6.798^{* * *}$ & $-2.144^{* *}$ \\
& $(1.020)$ & $(0.882)$ \\
Partner's Amount Sent & $-3.388^{* *}$ & 0.967 \\
Partner's Amount Sent*Female & $(1.511)$ & $(1.340)$ \\
& $0.176^{* * *}$ & $-0.158^{* * *}$ \\
Revealed Gender Treatment & $(0.0716)$ & $(0.0630)$ \\
& -0.0175 & $0.230^{* * *}$ \\
Revealed Gender Treatment*Female & $(0.107)$ & $(0.0953)$ \\
& 0.103 & -0.157 \\
Controls & $(0.439)$ & $(0.390)$ \\
& 0.141 & 0.224 \\
LR Chi & $(0.674)$ & $(0.603)$ \\
Observations & & \\
\hline \hline
\end{tabular}

Note: Censored Tobit estimation; standard errors in parentheses; the variable Beliefs measures subjects' beliefs about the amounts that their partner will send back for any possible amount the partner may have received. We approximated linearly subjects' beliefs and computed the corresponding slope to obtain the beliefs variable for each subject; controls include subject's amount sent in stage 1 and threshold 1 treatment dummy variables; statistical significance: $* \mathrm{p}<0.10$, ** $\mathrm{p}<0.05$, $* * * \mathrm{p}<0.01$. 


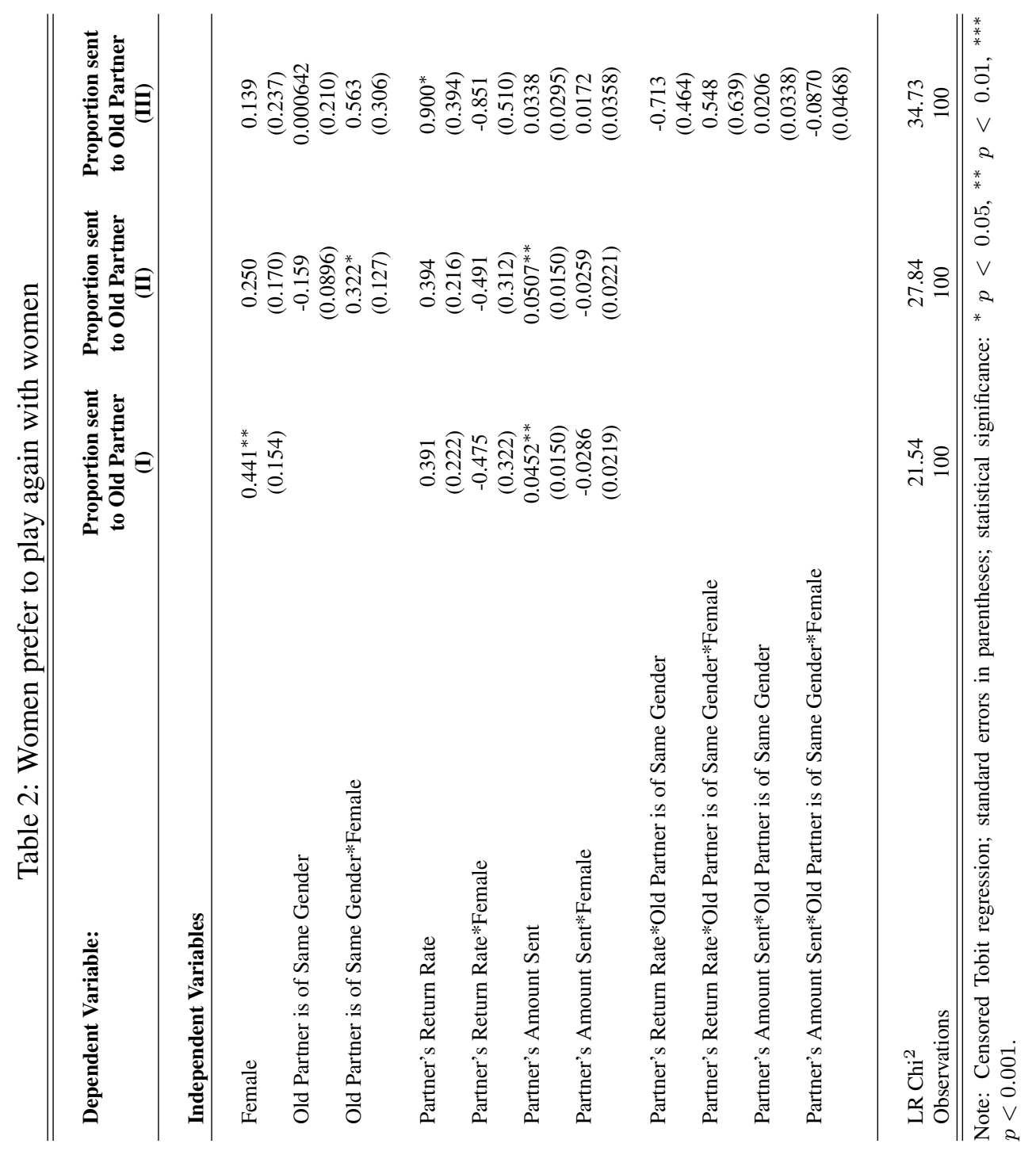




\subsection{The shape of men and women's real networks}

Our experimental design allowed us to leverage the particularities of the introductory week of the Goethe University Frankfurt to gain insights into overall differences of network formation between men and women. Owing to the anonymity in the experimental setup, we cannot use experimental behavior to predict which particular relationships would form, but we can test whether gender influences the likelihood that any pair of individuals will report a connection and see whether this is in line with the experimental evidence reported above.

Figure 4 provides a striking illustration of the power of the initial random allocation of individuals to introductory groups, and of the interaction of that allocation with the gender of the subjects. Some months after the experiment, subjects were asked to list up to 15 people they knew and to report whether these were friends or acquaintances. If the other party also reported a relationship, we label the relationship as "corroborated". Unfortunately, we cannot use the data to test whether there is a gender difference in the overall size of networks due to the way we elicited the networks; i.e. by "constraining" them to list a maximum of 15 people (a t-test reveals no significative gender difference in the number of reported relationships). However, we estimate dyadic regressions conditional on a set of controls and Figure 4 shows the corresponding estimated probabilities of reported and corroborated relationships and friendships for man-man, woman-woman and mixed-gender pairs. We use the term "relationship" to indicate either a friendship or an acquaintanceship without specifying which.

For relationships and friendships, both reported and corroborated, there is no difference between man-man, woman-woman and mixed-gender pairs when the subjects concerned were not allocated to the same introductory group. All such pairs report the same probability of a relationship several months later, a probability lying between 3 percent and 10 percent according to whether it was a relationship or a friendship, reported or corroborated. However, all pairs of individuals who were allocated to the same introductory group report substantially higher proportions of relationships later, and gender is a major factor in these. While two men who have been randomly assigned to the same introductory group are two-and-a-half times more likely both to report a subsequent friendship than two men who were in different groups, two women from the same group are around five times more likely to do so.

This is in line with the experimental results. Indeed, differential selectivity implies that women would be less prone to investing in new relationships, given that relationships have emerged by means of the introductory week activities, and differential opportunism would imply that women would react less to the behavior of the friends and acquaintances met through the introductory week, or to 
Figure 4: Women-women pairs from same introductory group are more likely to report friendship

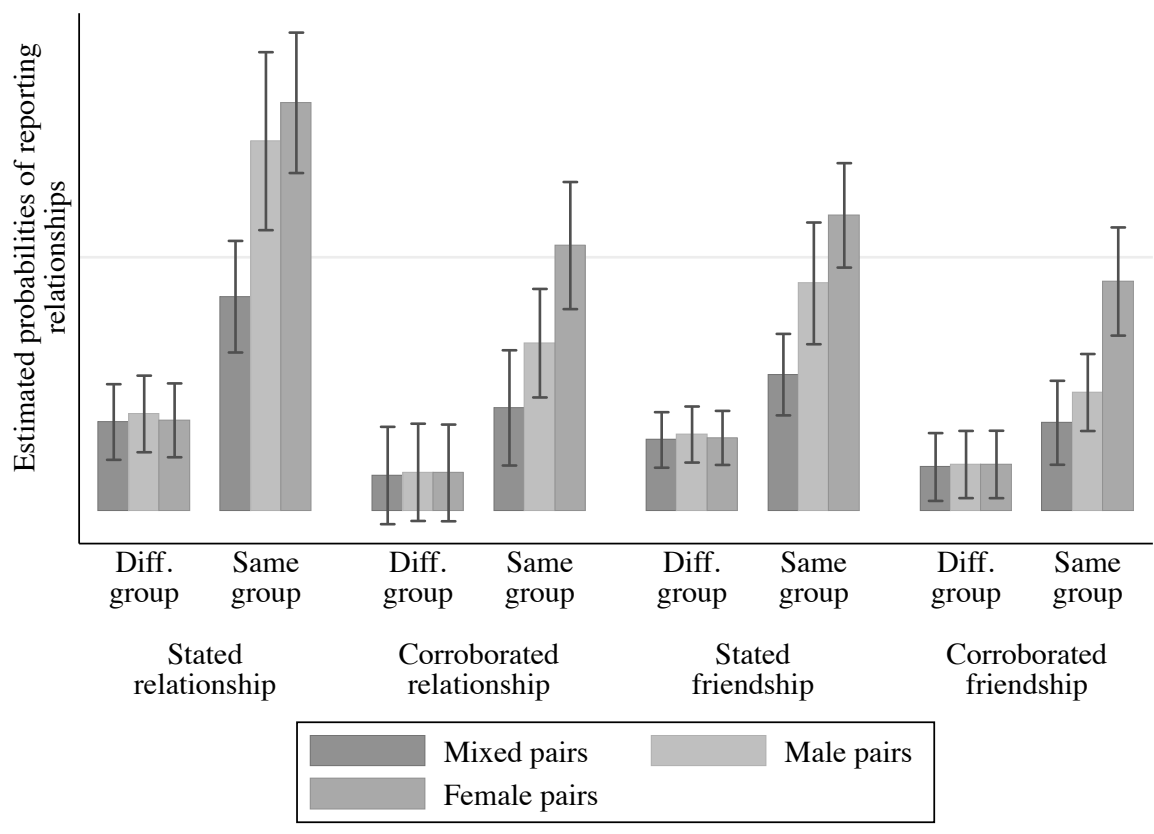

potential outside options of people they meet later in the university. Together the hypotheses imply that women's relationships should be more stable and more path dependent, in line with the evidence on reported relationships by subjects.

Figure 4 also depicts the auxiliary result that same sex relationships are more likely than mixed gender relationships, in line with the experimental evidence presented above. Such homophily can severely limit the size of women's networks in predominantly male settings, like the labor market for senior appointments.

Table 3 presents results of the formal econometric analysis. We estimate the following dyadic regression model:

$$
\begin{aligned}
\text { Relationship }_{i j} & =\gamma_{0}+\gamma_{1} \text { Pair_Characteristics }_{i j} \\
& +\gamma_{2} \text { Individual_Characteristics }_{i} \\
& +\gamma_{3} \text { Individual_Characteristics }_{j}+\zeta_{i j}
\end{aligned}
$$


Here Relationship Rij $_{i}$ is 1 if a relationship (reported or corroborated) exists and 0 otherwise. Pair_Characteristics $i j$ includes dummies for same introductory group, gender of the pair (male, female or mixed), wave ${ }^{3}$, and the interaction of same introductory group with gender of the pair. Individual_Characteristics ${ }_{i}$ records several individuals characteristics: age, Rhein-Main origin, risk aversion and general trust variables elicited in the first questionnaire 4 .

Table 3 gives the formal numbers used to produce Figure 4. First, we observe that the coefficient on the different introductory group dummy is negatively significant in all specifications. Any type of relationship is more likely to occur between any two students that were assigned to the same introductory group. This is unsurprising but reassures us that the data are telling a believable story. The introductory groups created unique opportunities for students to interact with each other and build their networks of university contacts.

Secondly, the coefficient on the mixed gender pair dummy is significantly negative in all specifications, suggesting that two males are more likely to cite each other than one male and one female ${ }^{5}$. Networks of university contacts show some patterns of homophily. Moreover, in the last three specifications, we can observe that female pairs are significantly more predictive than male pairs of the

\footnotetext{
${ }^{3}$ We control for whether the two individuals involved in the relationship belong to the first or second wave. There is only one case in which a student from the first wave cited a student from the second wave and the reported relationship was corroborated. We exclude this observation from our sample.

${ }^{4}$ More specifically, when we have information on the corroboration or not of the relationship (essentially when the cited individual also answered our questionnaire about her friends and acquaintances), we run the following regressions:

$$
\begin{aligned}
\text { Relationship }_{i j} & =\gamma_{0}+\gamma_{11} \mid \text { Pair_Characteristics }_{i j} \mid \\
& +\gamma_{12} \mid \text { Individual_Characteristics }_{i}-\text { Individual_Characteristics }_{j} \mid \\
& +\gamma_{13}\left(\text { Individual_Characteristics }_{i}+\text { Individual_Characteristics }_{j}\right)+\zeta_{i j}
\end{aligned}
$$
}

and when we could not know whether the relationship would have been corroborated or not (essentially when the cited individual did not answer our questionnaire), we estimate the following regressions:

$$
\begin{aligned}
\text { Relationship }_{i j} & =\gamma_{0}+\gamma_{11} \text { Pair_Characteristics }_{i j} \\
& +\gamma_{12}\left(\text { Individual_Characteristics }_{i}-\text { Individual_Characteristics }_{j}\right) \\
& +\gamma_{13}\left(\text { Individual_Characteristics }_{i}+\text { Individual_Characteristics }_{j}\right)+\zeta_{i j}
\end{aligned}
$$

As Fafchamps and Gubert (2007) explain, regressors must enter in a symmetric fashion so that the effect of individual characteristics is the same on the relationship between $i$ and $j$ and on the relationship between $j$ and $i$. Because individuals report several relationships and therefore dyadic observations are not independent, we use multi-way clustering in all regressions.

${ }^{5}$ A similar regression with the female pair dummy being the excluded category also shows that two females individuals are more likely to cite each other compared to one male and one female individuals. 
Table 3: Determinants of social connections

\begin{tabular}{lcccc}
\hline \hline $\begin{array}{l}\text { Dependent } \\
\text { Variable: }\end{array}$ & $\begin{array}{c}\text { Stated } \\
\text { Relationship }\end{array}$ & $\begin{array}{c}\text { Stated } \\
\text { Friendship }\end{array}$ & $\begin{array}{c}\text { Corroborated } \\
\text { Relationship }\end{array}$ & $\begin{array}{c}\text { Corroborated } \\
\text { Friendship }\end{array}$ \\
\hline Independent Variables & & & & \\
\hline Different introductory group & $-0.269^{* * *}$ & $-0.149^{* * *}$ & $-0.127^{* * *}$ & $-0.0710^{* * *}$ \\
& $(0.0384)$ & $(0.0265)$ & $(0.0243)$ & $(0.0139)$ \\
Female pair & 0.0378 & $0.0670^{* *}$ & $0.0962^{* * *}$ & $0.109^{* * *}$ \\
& $(0.0469)$ & $(0.0337)$ & $(0.0303)$ & $(0.0240)$ \\
Mixed gender pair & $-0.153^{* * *}$ & $-0.0899^{* * *}$ & $-0.0638^{* *}$ & $-0.0298^{*}$ \\
& $(0.0401)$ & $(0.0288)$ & $(0.0273)$ & $(0.0170)$ \\
Different introductory group* & -0.0441 & $-0.0704 * *$ & $-0.0968^{* * *}$ & $-0.109^{* * *}$ \\
Female pair & $(0.0474)$ & $(0.0341)$ & $(0.0311)$ & $(0.0245)$ \\
Different introductory group* & $0.145^{* * *}$ & $0.0846^{* * *}$ & $0.0607 * *$ & 0.0274 \\
Mixed gender pair & $(0.0401)$ & $(0.0287)$ & $(0.0276)$ & $(0.0173)$ \\
Controls & Yes & Yes & Yes & Yes \\
\hline Adjusted $R^{2}$ & & & & \\
Observations & 0.143 & 0.095 & 0.103 & 0.082 \\
\hline \hline
\end{tabular}

Note: OLS estimation with multi-way clustering; standard errors in parentheses; controls include age, Rhein-Main origin, risk aversion, general trust and wave dummy; significance levels: $* \mathrm{p}<0.10, * * \mathrm{p}<0.05, * * * \mathrm{p}<0.01$.

existence of a relationship, especially if the relationship is a friendship or is corroborated by the partner. This evidence is in line with the experimental finding that females have a preference for interacting with other females, while males do not necessarily, or a least to a lower extent.

Finally, and most interestingly of all, the coefficient on the interaction of the different introductory group with the female pair dummy is significantly negative in the last three specifications. Female pairs are much more likely than male pairs to develop friendships if they were in the same introductory group. This is again in line with the previous finding that women seem to prefer to invest relatively more in strong relationships (friendships or corroborated relationships). These last two pieces of evidence are consistent with the hypotheses on gender differences in the formation of weak and strong ties.

This evidence does not, of course, show that the differential selectivity and differential opportunism that we observed in the laboratory are the explanation for such gender differences in real social networking behavior among the same group of students. But if we had not observed such gender differences in the real networking behavior we would have had reason to doubt that our experimentally induced behavioral differences were important. Instead, their importance seems all the 
greater because of the way our subjects are behaving with respect to their real relationships.

\section{Conclusions}

Are there differences in the way men and women create social networks? And if so, what could explain these differences? We provide evidence for the role of women's preferences as compared to the impact of their economic constraints, which for well known reasons frequently differ from those of men.

If men are more opportunistic about the formation of networks, as our evidence suggests, they may benefit in two distinct ways: they may invest more in sustaining weak links in their social networks, and they may be more likely than women to call in favors from their casual acquaintances when looking for new employment. These behaviors are likely to make them more visible in their professional network - and in particular in high-skill professional networks - which might in turn generate career benefits.

It is plausible that sexual selection should have shaped preferences for social interactions we document, but, to our knowledge, we are the first to show a) that network formation preferences displayed in lab behavior are consistent with the predictions of sexual selection, and $b$ ) that the real network formation behavior of the same subjects who have played in the lab displays characteristics consistent with their laboratory behavior. Of course, trust games played over two rounds are a rather schematic representation of the complex behavior involved in creating and maintaining real life relationships. How far sexual selection has shaped this complex behavior remains a rich subject for future research.

\section{References}

Baumeister, Roy F and Sommer, Kristin L (1997). "What do men want? Gender differences and two spheres of belongingness: Comment on Cross and Madson (1997)". Psychological Bulletin, 122(1):38-44.

Beaman, Lori, Keleher, Niall, and Magruder, Jeremy (2015). "Do job networks disadvantage women? Evidence from a recruitment experiment in Malawi”. Working Paper, Northwestern University. 
Benenson, Joyce F (1993). "Greater preference among females than males for dyadic interaction in early childhood". Child Development, 64(2):544-555.

Bertrand, Marianne (2011). "New perspectives on gender". Handbook of labor economics, 4:15431590.

Booth, Alan (1972). "Sex and social participation". American Sociological Review, pages 183-193.

Brandts, Jordi and Charness, Gary (2000). "Hot vs. cold: Sequential responses and preference stability in experimental games". Experimental Economics, 2(3):227-238.

Brown, Meta, Setren, Elizabeth, Topa, Giorgio, et al. (2016). "Do informal referrals lead to better matches? Evidence from a firm's employee referral system". Journal of Labor Economics, 34(1):161-209.

Burks, Stephen V, Cowgill, Bo, Hoffman, Mitchell, and Housman, Michael (2015). "The value of hiring through employee referrals". The Quarterly Journal of Economics, 130(2):805-839.

Cingano, Federico and Rosolia, Alfonso (2012). "People I know: job search and social networks". Journal of Labor Economics, 30(2):291-332.

Croson, Rachel and Gneezy, Uri (2009). "Gender differences in preferences". Journal of Economic Literature, 47(2):448-474.

Darwin, Charles (1871). "The descent of man, and selection in relation to sex". In Bonner, J.T. and R.B., May., editors, Evolution and development. Princeton University Press., Princeton.

De Waal, Frans (1990). “Peacemaking among primates”. Harvard University Press.

Dustmann, Christian, Glitz, Albrecht, Schönberg, Uta, and Brücker, Herbert (2016). "Referral-based job search networks". The Review of Economic Studies, 83(2):514-546.

Eckel, Catherine C and Grossman, Philip J (2008). "Forecasting risk attitudes: An experimental study using actual and forecast gamble choices”. Journal of Economic Behavior \& Organization, 68(1):1-17.

Eckel, Catherine C and Wilson, Rick K (2000). "Whom to trust? Choice of partner in a trust game". Unpublished manuscript, Virginia Tech Department of Economics.

Fafchamps, Marcel and Gubert, Flore (2007). "The formation of risk sharing networks". Journal of Development Economics, 83(2):326-350. 
Fiedler, Marina, Haruvy, Ernan, and Li, Sherry Xin (2011). "Social distance in a virtual world experiment". Games and Economic Behavior, 72(2):400-426.

Granovetter, Mark S (1973). "The strength of weak ties". American Journal of Sociology, 78(6):1360-1380.

Granovetter, Mark S (1995). “Getting a job: A study of contacts and careers”. University of Chicago Press.

Holt, Charles A and Laury, Susan K (2002). "Risk aversion and incentive effects". The American Economic Review, 92(5):1644-1655.

Hrdy, Sarah Blaffer (2009). "Mothers and others: The evolutionary origins of mutual understanding”. Belknap Press.

Jackson, Matthew O (2008). "Social and economic networks", volume 3. Princeton university press Princeton.

Kosfeld, Michael (2004). "Economic networks in the laboratory: A survey". Review of Network Economics, 3(1):1-23.

Lalanne, Marie and Seabright, Paul (2016). "The old boy network: The impact of professional networks on remuneration in top executive jobs". SAFE Working Paper, Goethe University of Frankfurt.

Lindenlaub, Ilse and Prummer, Anja (2015). "Gender, social networks and performance”. Working Paper, Cambridge-INET Institute.

Low, Bobbi S (2001). “Why sex matters: A Darwinian look at human behavior”. Princeton University Press.

Mengel, Friederike (2016). "Gender differences in networking”. Working Paper, University of Essex.

Moore, Gwen (1990). “Structural determinants of men's and women's personal networks". American sociological review, pages 726-735.

Seabright, Paul (2012). "The war of the sexes: How conflict and cooperation have shaped men and women from prehistory to the present". Princeton University Press.

Slonim, Robert and Garbarino, Ellen (2008). "Increases in trust and altruism from partner selection: Experimental evidence". Experimental Economics, 11(2):134-153. 
Slonim, Robert and Guillen, Pablo (2010). "Gender selection discrimination: Evidence from a trust game”. Journal of Economic Behavior \& Organization, 76(2):385-405.

Trivers, Robert L. (1972). "Parental investment and sexual selection". In Campbell, Bernard, editor, Sexual Selection and the Descent of Man. Aldine Publishing Company, Chicago. 


\section{Appendix A: Supplementary tables and graphs}

Figure A1: Distribution of amounts sent to partners in the first stage by gender

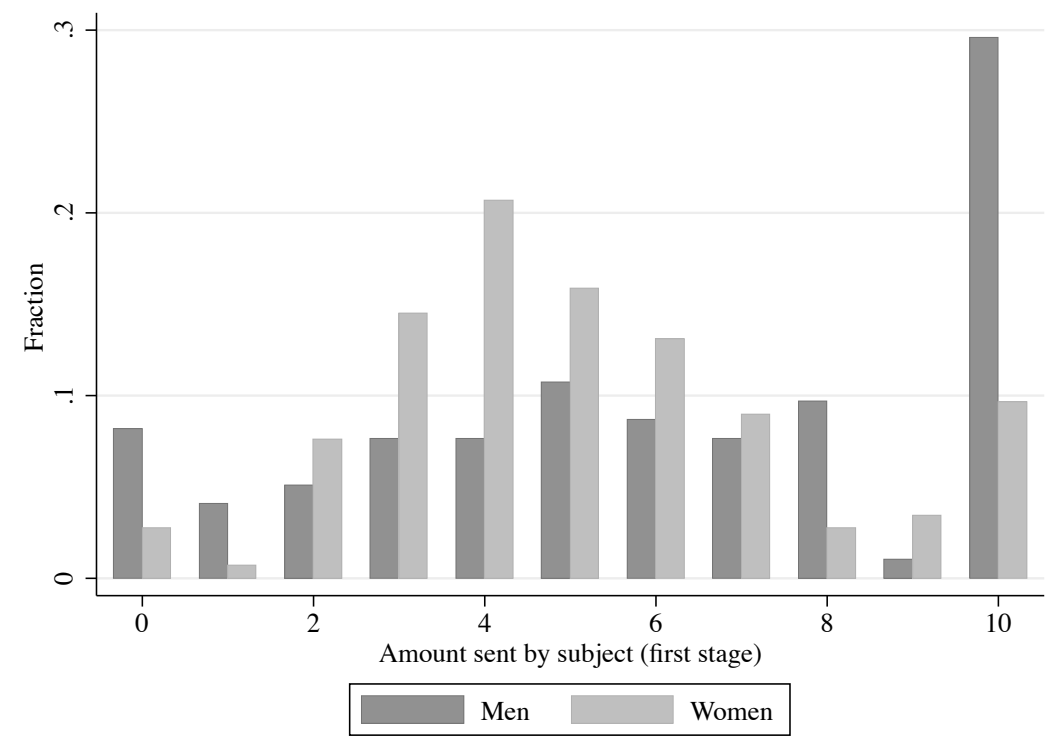

Figure A2: Distribution of amounts sent to new partners in the second stage by gender

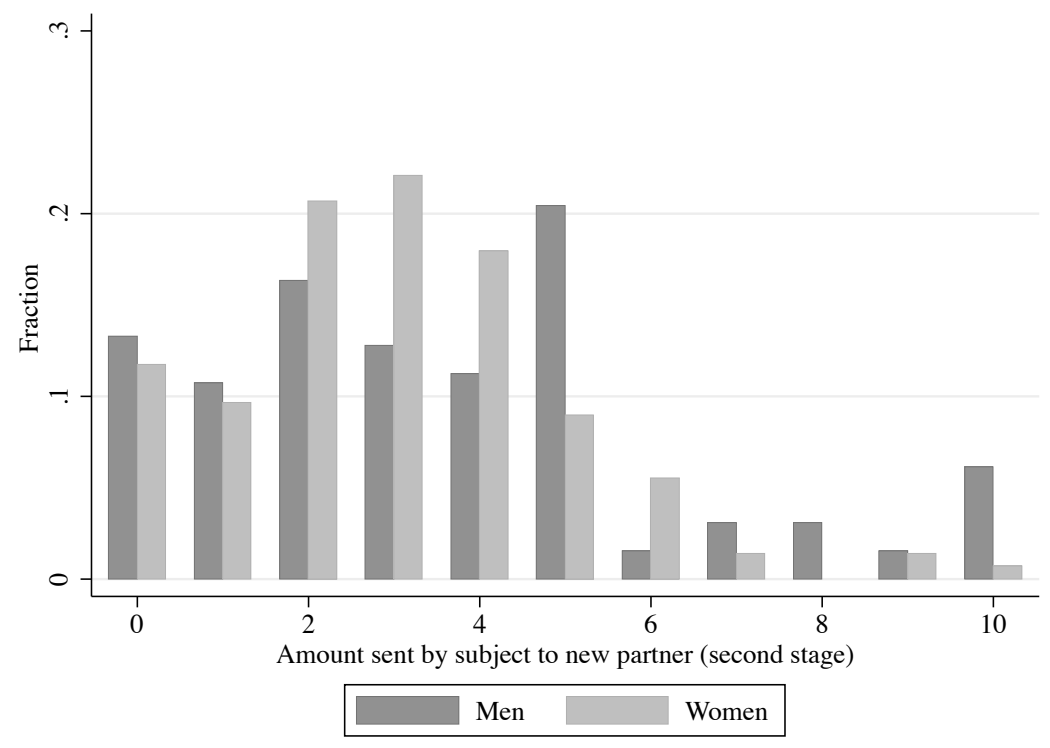




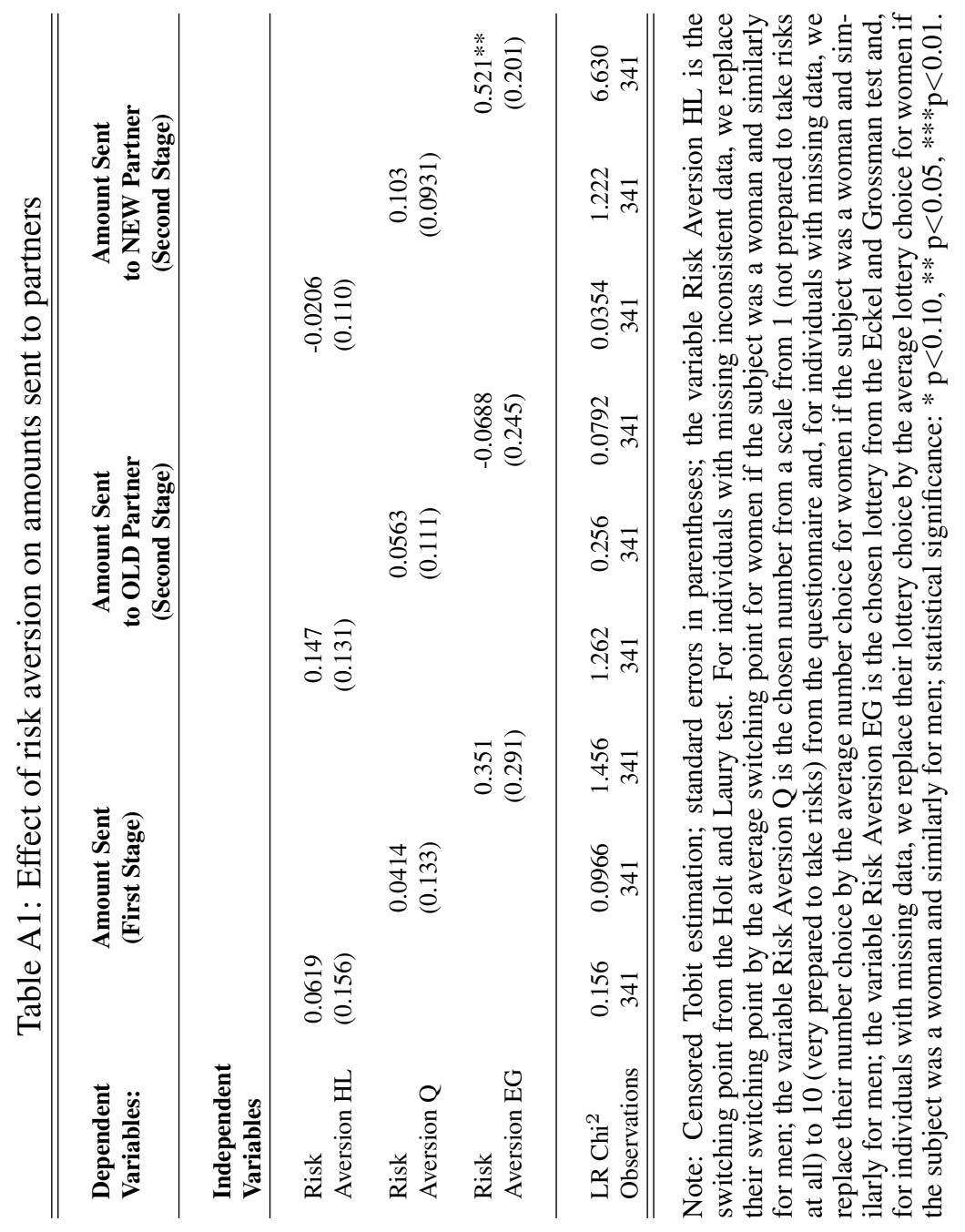


Appendix B: Experimental instructions for the baseline treatment 


\section{Instructions for the experiment}

Welcome to this experiment and thank you very much for participating. You have the opportunity to earn money in this experiment. The amount of your earnings depends directly on your decisions and on the decisions of other participants. It is very important that you do not talk during the experiment. We also ask you to place your bags underneath your chair and to turn off your mobile phone. Every decision you make is anonymous, which means that other participants will not receive any information about your identity.

This computerized experiment consists of two parts that will be explained to you by the experimenter. Please read the instructions in the same order in which the experimenter explains them and answer the control question after every step. Once everyone has answered the control questions, you are able to make your decisions.

Every participant receives $5 €$ for showing up, which will be paid at the end of the experiment. During the experiment you will have the chance to earn additional money. We will not refer to the money you earn as Euros, but as points. Your earnings will therefore be calculated in points. The total amount of points you achieve at the end of the experiment will be exchanged in the following rate:

1 point $=0.1$ Euro

You will receive your total earnings at the end of the experiment in cash. The payment is private so that no other participant knows how much you earned.

In the following we will explain the experiment in more detail. If you have any questions please raise your hand and wait until the experimenter comes to you. 


\section{Part 1}

\section{The Game}

In this part of the experiment you will be playing a game with one other participant. Both of you will play the game in the role of a sender and then in the role of a recipient.

The sender initially receives 10 points. He can then decide how many of his points he wants to send to the recipient. Every point the sender transfers to the recipient is tripled by the experimenters:

$\begin{array}{lllllllllll}\text { Points sent: } & 1 & 2 & 3 & 4 & 5 & 6 & 7 & 8 & 9 & 10 \\ \text { Points received: } & 3 & 6 & 9 & 12 & 15 & 18 & 21 & 24 & 27 & 30\end{array}$

The recipient does not receive any points at first. After the recipient receives the points from the sender, he decides how many points he wants to send back to the sender. Points that are transferred back are not tripled. This means that the sender receives the points the recipient returns to him.

The payments of the sender and recipient are calculated as following:

Payment of the sender $=10$ points - points sent by sender + points returned by receiver

Payment of the recipient $=$ (points sent by sender) $\times 3-$ points returned by receiver

You will now play this game with a randomly selected partner. Neither your own nor your partner's identity will be revealed.

\section{Sender}

You are now in the role of the sender. You have to decide how many of your points you want to send to your partner. You keep every point you do not send to your partner.

After finishing the following control question please raise your hand in order to have your answer checked by the experimenter. If the control question is answered correctly please click "next". You can make your decision once every participant has answered the control question correctly.

\section{Control question:}

You are in the role of the sender. Suppose you decided to send 2 points to your partner. How many points does your partner receive in this part?

Payment of the recipient: 


\section{Recipient}

You are in the role of a recipient. You have to decide how many points to return to the sender. The number of points you can return depends on the number of points you received from the sender. So please indicate, for every possible amount of points you could have received, how much you want to return to the sender. Note that

If the sender sends 0 points, then you are unable to return any points.

If the sender sends 1 point, then you are able to return between 0 and 3 points.

If the sender sends 2 points, then you are able to return between 0 and 6 points.

If the sender sends 10 points, then you are able to return between 0 and 30 points.

After answering the following control question please raise your hand in order to have your answer checked by the experimenter. If the control question is answered correctly please click "next". You can make your decision once every participant has answered the control question correctly.

\section{Control question:}

You are in the role of a recipient. The sender decided to send you 8 points. You have decided to return 2 points to your partner. What are your and your partner's payments?

Recipient's payment:

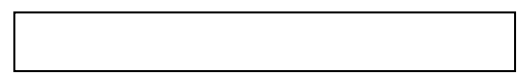

Sender's payment: 


\section{Estimate}

Just like you, your partner made a decision in the role of a recipient. Please estimate for every possible amount he could have received from you, how much he was willing to send back. Note that:

If you have sent 0 points as a sender, then your partner would not have been able to return any points.

If you have sent 1 point as a sender, your partner would have been able to return between 0 and 3 points.

If you have sent 2 points as a sender, your partner would have been able to return between 0 and 6 points.

If you have sent 10 points as a sender, your partner would have been able to return between 0 and 30 points.

After you made your decision one of your estimates will be randomly selected. If your estimate corresponds with the number of points your partner would have returned, you will receive 8 extra points. If the difference between your estimate and what your partner really would have sent back is up to 2 points, then you will receive 4 extra points. If the difference between your estimate and what your partner really would have sent back is up to 4 points, then you will receive 2 extra points. You do not receive any extra points if your estimate differs by more than 4 points from what your partner would have returned.

After answering the following control question please raise your hand in order to have your answer checked by the experimenter. If the control question is answered correctly please click "next“. You can make your decision once every participant has answered the control question correctly.

\section{Control question:}

Consider the case in which you transferred 8 points to your partner and your partner decided to return 10 points. How many extra points do you receive if...

... your estimate was 11 ?

... your estimate was 7 ?

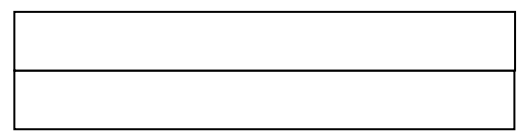




\section{Part 2}

\section{The Game}

In this part of the experiment you are part of a group of 3 participants, consisting of your partner from part 1, a new partner, and yourself. Everybody in your group plays a game similar to the one played in part 1 of the experiment, first in the role of a sender and then in the role of a recipient.

The sender once again receives 10 points. He then decides how many of his points he wants to send the old and/or to the new partner. Every point the sender sends to a recipient is tripled by the experimenters.

The recipient does not receive any points at first. After receiving points from his partner/s, he has to decide how many points he wants to return to the old partner and/or to the new partner. The points that are sent back are not tripled, which means that every sender receives the exact amount of points returned by the recipients.

Your identity as well as the identities of your old and new partner will not be revealed at any time.

\section{Sender}

You are now in the role of the sender. You have to decide how many of your points you want to transfer to send to your old partner and how many you want to send to your new partner. The total number of points you send cannot exceed 10 points. You keep every point that you do not send to a recipient.

After finishing the following control question please raise your hand in order to have your answer checked by an experimenter. If the control question is answered correctly please click "next". You can make your decision once every participant has answered the control question correctly.

\section{Control question:}

You are in the role of a sender. You decided to send 2 points to your old partner and 3 points to your new partner. How many points do you and your partners have?

Your points:

The points of your old partner as recipient:

The points of your new partner as recipient:

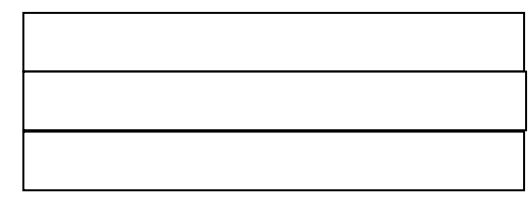




\section{Recipient}

You are now in the role of a recipient. You have to decide how many points you return to your old partner and how many you return to your new partner. The number of points you can return depends on the number of points you got from each sender. Please indicate, for possible amount you may receive, how much you want to send back to the sender. Note that

If a sender sends 0 points, then you are unable to return any points.

If a sender sends 1 point, then you are able to return between 0 and 3 points.

If a sender sends 2 points, then you are able to return between 0 and 6 points.

If a sender sends 10 points, then you are able to return between 0 and 30 points.

After finishing the following control question please raise your hand in order to have your answer checked by an experimenter. If the control question is answered correctly please click "next". You can make your decision once every participant has answered the control question correctly.

\section{Control question:}

You are in the role of a recipient. Your old partner decided to send you 8 points while your new partner sent you 9 points. You decided to send back 10 points to each partner. How many points do you and your partners have?

Your points:

The points of your old partner as sender:

The points of your new partner as sender:

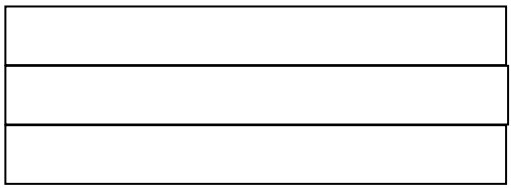




\section{Estimate}

Just like you, your partners made decisions in the role of a recipient. Please estimate for every possible amount they could have received from you, how much they were willing to send back. Note that:

If you have sent 0 points as a sender, then your partner would not have been able to return any points.

If you have sent 1 point as a sender, your partner would have been able to return between 0 and 3 points.

If you have sent 2 points as a sender, your partner would have been able to return between 0 and 6 points.

If you have sent 10 points as a sender, your partner would have been able to return between 0 and 30 points.

After you stated your estimates for each partner, two of your estimates, one for each partner, will be randomly selected. If your estimate corresponds with the number of points your partner would have returned, you will receive 8 extra points. If the difference between your estimate and what your partner really would have sent back is up to 2 points, then you will receive 4 extra points. If the difference between your estimate and what your partner really would have sent back is up to 4 points, then you will receive 2 extra points. You do not receive any extra points if your estimate differs by more than 4 points from what your partner would have returned.

After finishing the following control question please raise your hand in order to have your answer checked by an experimenter. If the control question is answered correctly please click "next". You can make your decision once every participant has answered the control question correctly.

\section{Control question:}

Consider the case in which you transferred 8 points to your partner and your partner decided to return 10 points. How many extra points do you receive if...

... your estimate was 9?

... your estimate was 13 ?

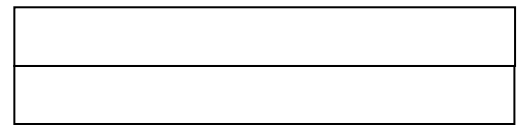




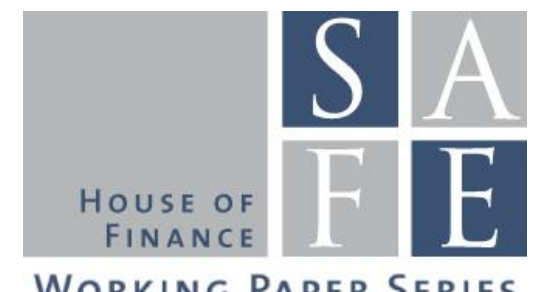

WORKING PAPER SERIES

\section{Recent Issues}

No. 167 Felix Noth, Ulrich Schüwer

No. 166 Monica Billio, Massimiliano Caporin, Roberto Panzica, Loriana Pelizzon

No. 165 Giovani Bonaccolto, Massimiliano Caporin, Roberto Panzica

No. 164 Raimond Maurer, Olivia S. Mitchell, Ralph Rogalla, Tatjana Schimetschek

No. 163 Giuliano Curatola, Michael Donadelli, Patrick Grüning

No. 162 Gabriele Camera, Alessandro Gioffré

No. 161 Tobin Hanspal

No. 160 Domenico Rocco Cambrea, Stefano Colonnello, Giuliano Curatola, Giulia Fantini

No. 159 Monica Billio, Michael Donadelli, Antonio Paradiso, Max Riedel

No. 158 Michael Donadelli, Renatas Kizys, Max Riedel

No. 157 Steffen Meyer, Linda Urban, Sophie Ahlswede

No. 156 Reint Gropp, Thomas Mosk, Steven Ongena, Carlo Wix

No. 155 Vahid Saadi
Natural disaster and bank stability: Evidence from the U.S. financial system

The impact of network connectivity on factor exposures, asset pricing and portfolio diversification

Estimation and model-based combination of causality networks

Optimal Social Security Claiming Behavior under Lump Sum Incentives: Theory and Evidence

Technology Trade with Asymmetric Tax Regimes and Heterogeneous Labor Markets: Implications for Macro Quantities and Asset Prices

Asymmetric Social Norms

The Effect of Personal Financing Disruptions on Entrepreneurship

Abandon Ship: Inside Debt and Risk-Taking Incentives in Bad Times

Which Market Integration Measure?

Globally Dangerous Diseases: Bad News for Main Street, Good News for Wall Street?

Does feedback on personal investment success help?

Bank Response To Higher Capital Requirements: Evidence From A QuasiNatural Experiment

Mortgage Supply and the US Housing Boom: The Role of the Community Reinvestment Act 